\title{
Utilization of Hydrophobic Interaction Affinity Nanosorbent for the Extraction Of Serotonin from Edible Plants
}

\author{
Yenilebilir Bitkilerden Serotoninin Özütlenmesi için Hidrofobik \\ Etkileşim Afinite Nanosorbentinin Kullanımı
}

\section{Research Article}

\author{
Mehmet Antmen', Nalan Tüzmen ${ }^{2 *}$, Mine Antep², Sinan Akgöl ${ }^{3}$ \\ ${ }^{1}$ Graduate School of Natural and Applied Sciences, Dokuz Eylül University, İzmir, Turkey. \\ ${ }^{2}$ Chemistry Department, Dokuz Eylül University, İmir, Turkey. \\ ${ }^{3}$ Biochemistry Department, Ege University, İzmir, Turkey.
}

\section{A B S T R AC T}

\begin{abstract}
The aim of this study was to evaluate the extraction performance of poly(hydroxyethyl methacry-latemethacryloyl-(L)-tryptophan methyl ester) poly(HEMA-MAT)] nanostructures for serotonin from edible plants by a series of batch experiments. Average size of nanostructures was found as $100 \mathrm{~nm}$ with poly-dispersity index of 1.189 using zeta size analysis results. Maximum serotonin uptake capacity of the nanostructures was found to be $2901.4 \pm 65.9 \mathrm{mg} / \mathrm{g}$ at $\mathrm{pH}$ 6.0. Applicability of this nanosorbent for the extraction of serotonin in banana and tomato before HPLC analysis was also studied and the level of serotonin was determined as 86.26 $\mathrm{mg} / \mathrm{g}$ for banana and $36.02 \mathrm{mg} / \mathrm{g}$ for tomato samples.
\end{abstract}

\section{Key Words}

Serotonin, affinity nanosorbent, extraction, hydrophobic interaction chromatography.

\section{öz}

u çalışmanın amacı, bir seri kesikli sistem deneylerle poli (hidroksietil metakrilat-metakriloil- (L) -triptofan metil ester) poli (HEMA-MAT)] nano-yapılarının yenilebilir bitkilerden serotonin için özütleme performansını değerlendirmektir. Polidispersiyon indeksi 1.189 olan nanoyapıların ortalama boyutu, zeta boyut analizi

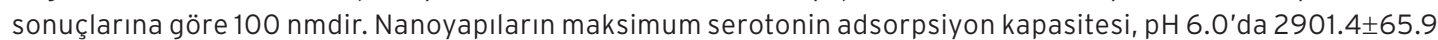
$\mathrm{mg} / \mathrm{g}$ olarak bulunmuştur. Bu nanosorbentin, HPLC analizi öncesi muz ve domatesde serotonin özütlemesi için uygulanabilirliği de araştırımış. Serotonin seviyesi muz için 86.26 mg/g, domates numuneleri için $36.02 \mathrm{mg} / \mathrm{g}$ olarak tespit edilmiştir.

Anahtar Kelimeler

Serotonin, afinite nanosorbent, özütleme, hidrofobik etkileşim kromatografisi.

Article History: Received: Mar 23, 2017; Revised: Aug 15, 2017; Accepted: Oct 11, 2017; Available Online: Dec 25, 2017. DOI: $10.15671 /$ HJBC.2018.186

Correspondence to: N. Tüzmen, Chemistry Department, Dokuz Eylül University, İzmir, Turkey. 


\section{INTRODUCTION}

erotonin (5-hydroxytryptamine, 5-HT) is a $\checkmark$ well-recognized bioactive indolamine and has a broad array of activities in various animal cells as a neurotransmitter, hormone, and mitogenic factor. It also acts in immunomodulatory and anti-inflammatory processes in animal cells [1,2]. Serotonin plays an important role in the modulation of sleep, anxiety, aggression, mood, sexuality, appetite, and also in muscle contraction or blood pressure regulation [3-5]. On the other hand, exogenous serotonin acts on nutrient and intestinal electrolyte transport, and body temperature $[6,7]$. It has been shown with a number of studies that serotonin and related indolamines are present in different parts of plants such as leaves, stems, roots, flowers, fruits, and seeds at varying but significant amounts $[8,9]$. With the finding of physiological role of serotonin and other related indolamines in animals, research on compounds with different bioactive roles naturally present in edible plants has great importance in respect of diet and health.

It has been reported that the analysis of serotonin in edible plants exhibits some difficulties. Firstly, the analytical methods must be sensitive because the amount of serotonin in some plant samples is very low. Secondly, it is difficult to select an extraction method with complete recovery and accurate results [1]. Several different methods such as high performance liquid chromatography with UV [10-12], electro-chemical [13,14], or fluorescence detections [15-17], radioimmunoassay (RIA) [18] and thin layer chromatography [19] have been widely used for the determination of serotonin in edible plants. Applications of capillary electrophoresis (CE) with the similar sensitivity of HPLC have also been reported, but CE and RIA have not been used extensively in plant analysis [18,20-22]. Although the use of gas chromatography coupled to mass spectrometry (GC-MS) has improved sensitivity and selectivity, necessity of derivatization presents a disadvantage and limits its usage $[23,24]$. Because of the difficulties mentioned above, sensitive and specific techniques are required and also extraction of the compounds present mostly at low levels with high recovery is absolutely necessary. As known, sample preparation has an important role in the whole analytical process for the extraction and concentration of target analytes. A suitable pretreatment technique can also cope with matrix interferences for the improvement of the determinability of the analytical technique [25].

Sorbent-based extraction (also known as solid phase extraction, SPE) which is one of the typical pretreatment techniques is more prevalent than solvent-based approach because of using less toxic solvent [26]. On the other hand, SPE integrated with high-performance liquid chromatography (HPLC) presents a lot of advantages for the determination of the trace analytes [26]. So far, a great variety of sorbents for SPE has been arised. For the extraction of all kinds of compounds from complex matrices, surface modified silicas (C8, C18) [27], macroporous polymeric materials [28], graphene-based materials [29], carbon nanotubes [30], and polymeric ionic liquids (PIL) [31] have been widely utilized. Besides, it has been stated in the literature that commercial solid phase sorbents (C8, C18, aluminum-backed silica gel 60) have only been used for the extraction of serotonin [32-34], but they unfortunately show a lack of selectivity. Therefore, development of selective sorbent material for SPE of serotonin has a critical importance.

Inthepastfew decades, affinity chromatographic sorbents have been well-recognized materials and have attracted intense attention for the extraction, separation, purification and analytic characterization of various kinds of compounds, both in the laboratory and on an industrial scale [35]. Recently, nano-sized sorbents have been intensively studied because of their potential applications in many areas like biology, medicine and environment, because nano-sized materials have advantages being highly strong and cheaper, providing larger specific surface area and having high binding capacity for target molecules $[36,37]$. In this study, the novel hydrophobic interaction affinity (HIA) sorbent was applied in order to extract serotonin before the efficient determination of it in edible plants. For this aim, N-methacryloyl-(L)tyrptophan (MAT) and 2-hydroxyethyl methacrylate (HEMA) monomers were used in surfactant free emulsion polymerization for the synthesis of poly(HEMA-MAT) nanostructures with the size of $100 \mathrm{~nm}$. Characterization of the poly(HEMA-MAT) nanostructures were performed by surface area 
calculations, elemental analysis, zeta charge-zeta potential, SEM, and FTIR. Afterward, the poly(HEMAMAT) nanostructures were used for the extraction of serotonin from aqueous solutions and edible plant samples such as banana and tomato via adsorption. Desorption of serotonin and the stability of these materials were also tested.

\section{EXPERIMENTAL}

\section{Materials}

Hydroxyethylmethacrylate (HEMA) (Sigma Chem. St. Louis, USA) and ethylene glycol dimethacrylate (EGDMA, Aldrich, Munich, Germany) were distilled under vacuum $(100 \mathrm{mmHg})$. Serotonin was supplied by Sigma (St Louis, USA). All other chemicals were of the highest purity and used without further purification. Ultra-pure water filtered by Millipore S.A.S 67120 Molsheim-France was used for all experiments unless otherwise stated. The laboratory glassware was rinsed with water before use and dried in a dust-free environment.

\section{Preparation of Poly(HEMA-MAT) Nanostructures}

Poly(HEMA-MAT) nanostructures were prepared by surfactant-free emulsion polymerization as reported in our previous reports [37,38]. A typical polymerization procedure may be summarized as follows: Polyvinyl alcohol (PVA) (0.5 g) used as a stabilizer was dissolved in $50 \mathrm{~mL}$ deionized water to prepare the continuous phase. After adding the co-monomer mixture to this dispersion phase, the combination was mixed in an ultrasonic bath for about half an hour. Before polymerization, potassium persulfate was added to the solution as an initiator and polymerization was realized in a constant temperature shaking bath at $70^{\circ} \mathrm{C}$, under nitrogen atmosphere for $24 \mathrm{~h}$. To remove the unreacted monomers, poly(HEMA-MAT) nanostructures washed with methanol and water several times. Poly(HEMA) nanostructures were prepared by the same formulation without MAT co-monomer. In this study, poly(HEMA-MAT) nanostructures with the size range of $100 \mathrm{~nm}$ were used as a hydrophobic interaction affinity sorbent for the extraction of serotonin via adsorption. Fourier transform infrared spectroscopy (FTIR) spectra of the nanostructures were obtained by using a FTIR spectrophotometer (FTIR 8000 Series, Shimadzu, Japan) after mixing the dried nanostructures (about $0.1 \mathrm{~g}$ ) with $\mathrm{KBr}(0.1$ g, IR Grade, Merck, Germany), and pressing into a pellet form. Figure 1 shows the hypothetic structure of poly(HEMA-MAT) nanostructures.

\section{Serotonin Adsorption Studies from Aqueous Solutions}

Serotonin adsorption experiments were carried out in a batch system at room temperature while stirring continuously. To determine the effect of contact time on adsorption capacity, adsorption studies were completed in the changing time interval (0-60 min). The effect of the $\mathrm{pH}$ was studied in the range of 3.0-7.0 using $0.1 \mathrm{M}$ citrate buffer for $\mathrm{pH}$ 3.0-4.0, $0.1 \mathrm{M}$ acetate buffer for $\mathrm{pH}$ 4.0-5.0, and 0.1 M phosphate buffer for 6.0-8.0. The effect of the initial concentration of serotonin on the adsorption capacity was also studied. For this goal, $10 \mathrm{~mL}$ of aqueos solutions containing different amounts of serotonin (in the range of 1-100 $\mu \mathrm{g} / \mathrm{mL}$ ) were treated with the poly(HEMAMAT) nanostructures at room temperature and magnetically stirred at a speed of $200 \mathrm{rpm}$. To investigate the effect of temperature on adsorption capacity, temperature values were changed between $4^{\circ} \mathrm{C}$ and $45^{\circ} \mathrm{C}$. To conclude the effect of ionic strength on serotonin adsorption, concentration of $\mathrm{NaCl}$ was changed between $0.1 \mathrm{M}$ and $1.5 \mathrm{M}$. Initial and final serotonin concentrations were determined by liquid chromatographic

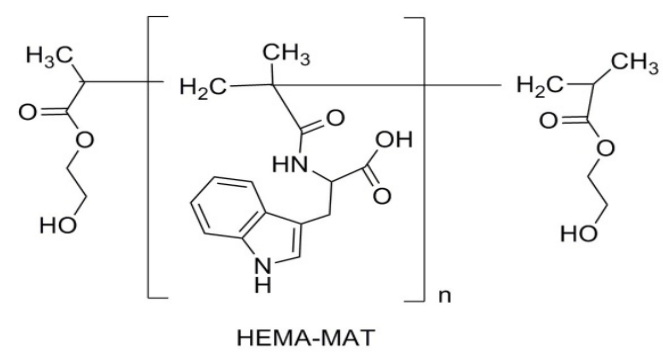

Figure 1. Hypothetic structure of poly(HEMA-MAT) nanostructures. 
analysis. The serotonin adsorption capacity of poly(HEMA-MAT) nanostructures was calculated by the following equation:

$$
q=\left(C_{0}-C\right) V / m
$$

where $C_{0}, V$, and $m$ are respectively the initial serotonin concentration $\left(\mathrm{mg}^{\mathrm{L}} \mathrm{L}^{-1}\right)$, volume of solution $(\mathrm{L})$, and mass of the polymer $(\mathrm{g})$.

The serotonin adsorption experiments were carried out in three replicates. The mean values and standard deviations were determined using standard statistical methods for each set of data. The margin of error was determined by calculating confidence intervals of $95 \%$ for each set of samples.

\section{Chromatographic Determination of Serotonin}

Serotonin concentrations were determined by high performance liquid chromatography (HPLC) method of Hosseinian et al. [11]. Chromatographic analysis was performed by a Hewlett Packard Agilent 1100 series HPLC system (HP Corporation, Germany) connected with a G1311A isocratic pump, a G1322A degasser and a G1315B diode array detector ( $500 \mathrm{~nL}, 10 \mathrm{~mm}$ path length). A reversed-phase ACE C4 analytical column, 250 $\mathrm{mm} \times 4.6 \mathrm{~mm}, 5 \mu \mathrm{m}$, was employed. The mobile phases were: $A, 0.1 \%$ acetic acid in double deionized water and $B, 0.1 \%$ acetic acid in acetonitrile with a A:B proportion of 90:10. The flow rate was adjusted at $0.5 \mathrm{~mL} / \mathrm{min}$. The column temperature was $25^{\circ} \mathrm{C}$. The injection volume and run time were $20 \mu \mathrm{L}$ and $30 \mathrm{~min}$, respectively. The chromatographic data was collected at 280 $\mathrm{nm}$. At these chromatographic conditions, the retention time of serotonin was determined as $9.6 \mathrm{~min}$.

\section{Desorption of Serotonin}

Different desorption agents [0.5-1.5 M NaCl, 0.5-1.5 M NaSCN and 1\% triethylamine (TEA)] were examined to carry out the most efficient desorption. The serotonin adsorbed poly(HEMAMAT) nanostructures were incubated in desorption medium at room temperature for $6 \mathrm{~h}$. Desorption ratio was determined using the amounts of serotonin adsorbed on the nanostructures and the final serotonin concentration in the desorption medium.
Desorptio ratio $(\%)=$ Amount of serotonin Desorbed $/$ Amount of serotonin absorbed

The nanostructures were washed with deionized water for $2 \mathrm{~h}$ and conducted with the buffer used in the adsorption and were then reused for serotonin adsorption.

\section{Extraction of Serotonin from Banana and Tomato Using Poly(HEMA-MAT) Nanostructures}

Food samples (banana and tomato) were purchased at local commercial markets. A portion of about $0.25 \mathrm{~g}$ of the edible part of food samples was homogenized in $0.01 \mathrm{M}$ acetic acid containing $10 \mathrm{~g} / \mathrm{L}$ each of EDTA, ascorbic acid, and sodium peroxomonosulfate $\left(\mathrm{Na}_{2} \mathrm{SO}_{5}\right)$ [39]. The homogenates of food samples were centrifuged for $40 \mathrm{~min}$ at $10000 \times \mathrm{g}$ and then the sample supernatants as $400 \mu \mathrm{L}$ were added to $100 \mu \mathrm{L}$ of poly (HEMA-MAT) nanostructures and shaked for 30 min at room temperature. After centrifugation of last mixture at $10000 \times \mathrm{g}$ for $40 \mathrm{~min}$, a volume of $20 \mu \mathrm{L}$ of the final extract filtered through a $0.2 \mu \mathrm{m}$ PTEF membrane was injected in the HPLC system and analyzed under conditions described above.

\section{RESULTS AND DISCUSSION}

\section{Properties of Poly(HEMA-MAT) Nanostructures}

Nanostructures may result in high extraction yield because of their larger specific surface area. So it may be functional to prepare nanostructures with large surface area and apply them as suitable sorbents for the extraction of bioactive molecules. The characterization studies for the nanostructures were conducted and reported in detailed in our previous study [38]. Properties of poly(HEMA-MAT) nanostructures can be summarized as below: The p(HEMA-MAT) nanostructures in the size of $100 \mathrm{~nm}$ in diameter have a good spherical shape, uniform size and non-porous structure. Non-porous structure of the adsorbents is a great advantage, because significant intraparticle diffusion resistances are absent. So, this is particularly useful for the rapid 


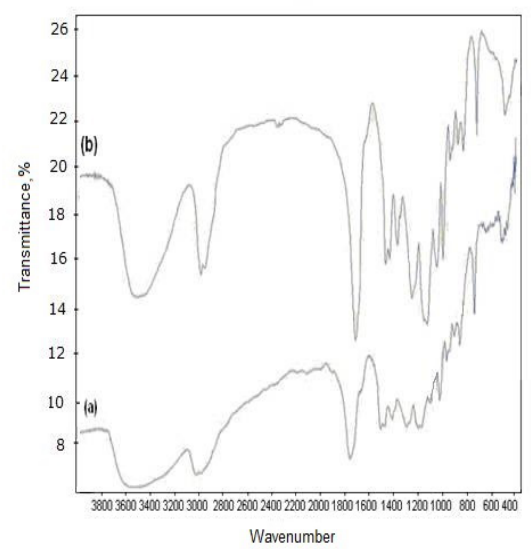

Figure 2. FTIR spectra of (a) poly(HEMA), (b) poly (HEMAMAT) nanostructures.

separations [40]. The specific surface areas of poly(hydroxyethylmethacrylate) [p(HEMA)] and $p$ (HEMA-MAT) nanospheres were determined as $1856 \mathrm{~m}^{2} / \mathrm{g}$ and $1914 \mathrm{~m}^{2} / \mathrm{g}$, respectively. The amount of $\mathrm{N}$-methacryloylamidotryptophan (MAT) incorporated to polymer was determined as $1.95 \mathrm{mmol} / \mathrm{g}$ polymers by using nitrogen stoichiometry [38]. MAT was selected as the hydrophobic affinity ligand. Hydrophobic interaction chromatography (HIC) makes use of the hydrophobicity of biomolecules stimulating their separations on the basis of hydrophobic interactions between immobilized hydrophobic ligands and nonpolar regions on the surface of the biomolecules. HIC can use various types of hydrophobic molecules having side chains of nonpolar amino acids like tryptophan, methionine, alanine, and phenylalanine as a ligand [41].

FTIR spectrum given in Figure 2 shows the incorporation of MAT into the structure of poly(HEMA-MAT) nanostructures. The peak observed at around $3500 \mathrm{~cm}^{-1}$ took its source from the stretching vibration of hydroxyl groups of both poly(HEMA) and poly(HEMA-MAT) nanostructures. The peak at this wavenumber of poly(HEMA-MAT) nanostructures is sharper than the peak of the poly(HEMA) nanostructures because of the extra stretching vibration of the hydroxyl group of MAT in the poly(HEMA-MAT) nanostructures. Reason of the change in the FTIR spectrum of poly(HEMAMAT) nanostructures around $3000-3400 \mathrm{~cm}^{-1}$ is the presence of $\mathrm{N}-\mathrm{H}$ stretching and aromatic $\mathrm{C}-\mathrm{H}$ stretching bands of L-tryptophan. Furthermore, the characteristic stretching vibration band of carbonyl group at $1700 \mathrm{~cm}^{-1}$ in poly(HEMA-MAT) nanostructures was excessively sharp because of existence of extra carbonyl groups. The band observed around $749.8 \mathrm{~cm}^{-1}$ was assigned to the aromatic characteristic of MAT. These data confirmed the presence of MAT in the structure of poly(HEMA-MAT) nanostructures.

\section{Optimization of Serotonin Adsorption Effect of Contact Time}

As shown in Figure 3, the serotonin adsorption capacity increased with the contact time and then reached a plateau value after the contact time of $30 \mathrm{~min}$. Therefore, equilibration time was taken in consideration as $30 \mathrm{~min}$. Afterall in the following experiments, the contact time was adjusted to 30 min to ensure adsorption equilibrium.

\section{Effect of pH}

Batch adsorption equilibrium studies were performed at different pHs in the range of 3.0-7.0 at $25^{\circ} \mathrm{C}$ for the determination of the effect of $\mathrm{pH}$ on the adsorption of serotonin onto poly(HEMAMAT) nanostructures. As seen in Figure 4, the amount of adsorbed serotonin increased from $\mathrm{pH}$ 3.0 to 6.0 and decreased dramatically when the $\mathrm{pH}$ was increased to 7.0 and maximum adsorption of serotonin was observed at $\mathrm{pH}$ 6.0. The $\mathrm{pH}$ can be a significant factor influencing the adsorption of biomolecules in hydrophobic interaction chromatography (HIC) [42-45]. Usually, the hydrophobic interaction between biomolecules and the hydrophobic ligands decreases with the increasing $\mathrm{pH}$, because hydrophilicity increases in conjuction with the changing charge of the biomolecule $[45,46]$. Near pH 6.0, it can be concluded that the hydrophobic interactions between the serotonin molecules and the poly(HEMA-MAT) nanostructures, and the intramolecular interaction between the serotonin

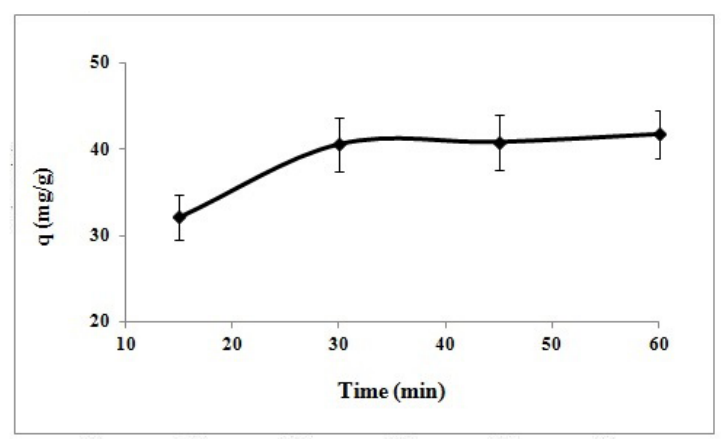

Figure 3. Effect of contact time on adsorption ( $\mathrm{pH}: 6.0, \mathrm{C}_{\mathrm{i}}$ $10 \mu \mathrm{g} / \mathrm{mL}, \mathrm{T}: 25^{\circ} \mathrm{C}$ ). 


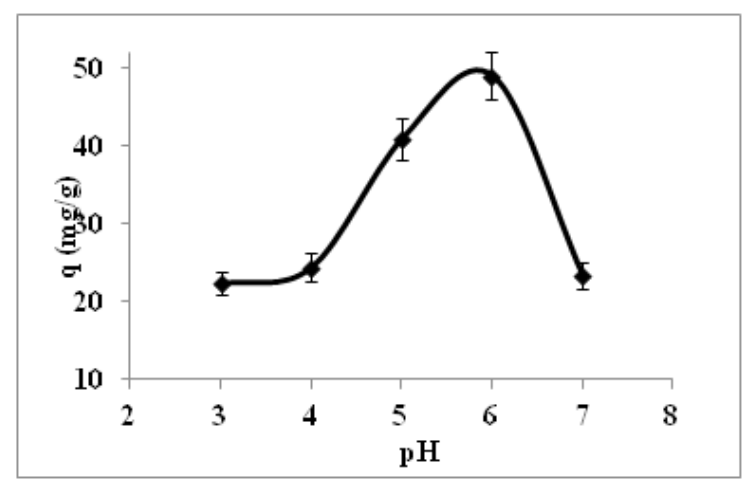

Figure 4. Effect of $\mathrm{pH}$ on adsorption $\left(\mathrm{C}: 10 \mu \mathrm{g} / \mathrm{mL}, \mathrm{T}: 25^{\circ} \mathrm{C}\right.$ t: 30 min).

molecules are high and these interactions enable the close packing of serotonin molecules on the poly(HEMA-MAT) nanostructures. These hydrophobic interactions may be the result of the attraction of the non-polar side chains of the serotonin molecules by the hydrophobic surface of the poly(HEMA-MAT) nanostructures. Beside, these interactions may arise from from the serotonin-serotonin interactions between the hydrophobic side chains of neighbouring serotonin molecules adsorbed poly(HEMA-MAT) nanostructures surface. On the other hand, the lower amount of serotonin adsorbed at a pH 5.0 can be explained in terms of the net positive charge on the serotonin molecules. With decreasing the $\mathrm{pH}$, the net positive charge on the serotonin increases and electrostatic repulsion between the $-\mathrm{NH}_{3}{ }^{+}$of the serotonin molecule occur. It can be concluded that the formation of $-\mathrm{NH}_{3}{ }^{+}$partially hinders the hydrophobic interaction between the serotonin and adsorbent. Thus, the serotonin molecule need more space and the amount of serotonin adsorbed is reduced. Also, the reason

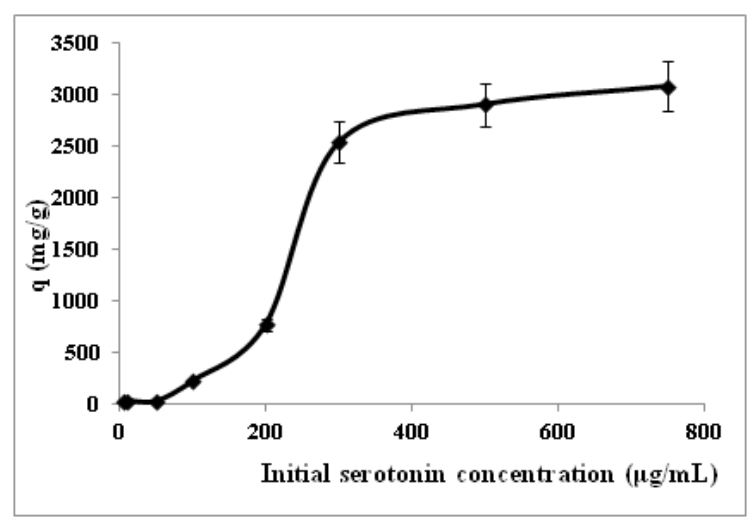

Figure 5. Effect of initial serotonin concentration on adsorption ( $\left.\mathrm{pH}: 6.0, \mathrm{~T}: 25^{\circ} \mathrm{C}, \mathrm{t}: 30 \mathrm{~min}\right)$. of low adsorption at pH values below 4.0 could be due to degradation of serotonin, because serotonin is not stable at acidic $\mathrm{pH}$. At $\mathrm{pH} 7.0$, basic properties of amine group in the serotonin structure increases and this amine group may attack to the phenol group of serotonin. So, phenol deprotonation may occur, and hence, the electrostatic interaction between the negatively and positively charged groups of the neighbouring serotonin molecules results in a reduced amount of adsorption.

\section{Effect of Serotonin Concentration}

Figure 5 shows the effect of the initial serotonin concentration on the adsorption capacity of the poly(HEMA-MAT) nanostructures. We observed that the amount of adsorbed serotonin increased with the initial concentration and then reached a saturation value of $500.0 \mu \mathrm{g} / \mathrm{mL}$. Maximum adsorption capacity of the poly(HEMA-MAT) nanostructures was found to be $2901.4 \pm 65.9$ $\mathrm{mg} / \mathrm{g}$. It should also be paid attention that the insignificant amounts of serotonin were non-specifically adsorbed on the plain of the poly(HEMA) nanostructures $(13.8 \pm 0.9 \mathrm{mg} / \mathrm{g}$ for serotonin). On the other hand, the serotonin adsorption capacity of the prepared materials was significantly increased by the incorporation of MAT groups. The reason could be the strong specific hydrophobic interactions between serotonin and MAT groups.

\section{Effect of Temperature}

Temperature is a considerable parameter in adsorption reactions. Because of the exothermic nature of the adsorption, adsorption capacity decreases with increasing temperature and molecules adsorbed earlier on a surface incline to be desorbed from the surface at higher temperatures. The studies are usually carried out at approximately $25-30^{\circ} \mathrm{C}$, sometimes in the range 4 to $55^{\circ} \mathrm{C}$ [46-49]. In this study, adsorption studies of serotonin were followed out over a range of temperatures from 4 to $45^{\circ} \mathrm{C}$. As seen in Figure 6 , the adsorption capacity of the prepared materials decreased about $45.1 \%$ from 4 to $45^{\circ} \mathrm{C}$. According to the theories developed for the interaction of hydrophobic solutes in water, it was suggested that the interaction increases with increasing temperature, because 


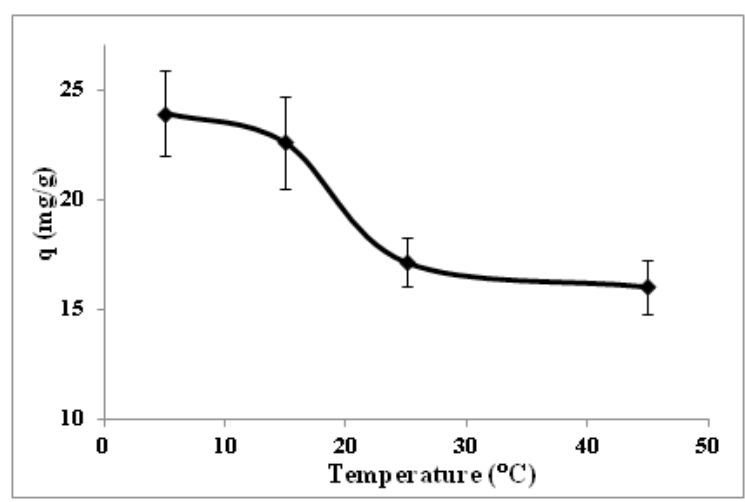

Figure 6. Effect of temperature on adsorption ( $\mathrm{pH}: 6.0$, $\left.\mathrm{C}_{\mathrm{i}}: 10 \mu \mathrm{g} / \mathrm{mL}, \mathrm{t}: 30 \mathrm{~min}\right)$.

the binding of biomolecules to HIC adsorbents is an entropy driven process $[\Delta G=(\Delta \mathrm{H}-\mathrm{T} \Delta \mathrm{S})]$. However, an opposite effect indicating that the role of temperature in $\mathrm{HIC}$ is of a complex nature has taken part in the literature [50].

In order to predict the impact of temperature on serotonin adsorption, the enthalpy value $(\Delta H)$ for the adsorption of serotonin onto the poly(HEMAMAT) nanostructures was calculated. Firstly, the distribution coefficient $K_{d}$ [51] was determined using the following equation:

$$
K_{d}=\frac{Q_{e q}}{C_{e q}} K_{d}=\frac{Q_{e q}}{C_{e q}}
$$

$Q_{e q}$ is the mass of adsorbed serotonin per unit mass of adsorbent. $C_{\text {eq }}$ is the equilibrium concentration of serotonin $(\mathrm{mg} / \mathrm{mL})$. Then, the enthalpy value for the adsorption of serotonin can be estimated according to Van't Hoff equation: $\frac{\partial \log K_{d}}{\partial\left(\frac{1}{T}\right)}=-\Delta H / 2.303 R$

A linear form can be obtained by integrating and rearranging of Eq. (5)

$$
\log \mathrm{K}_{\mathrm{d}}=-\frac{\Delta H}{2.303 R T}+\text { constant }
$$

The enthalpy of the serotonin adsorption onto the poly (HEMA-MAT) nonostructures was calculated from the plots of log $K_{d}$ vs. $1 / T$ as $-11.3 \mathrm{~kJ} / \mathrm{mol}$. This data indicated that the adsorption of serotonin onto the poly (HEMA-MAT) nanostructures was really exothermic and so it was an expected result to observe a decrease in the adsorption capacity as the temperature increases from 4 to $45^{\circ} \mathrm{C}$.

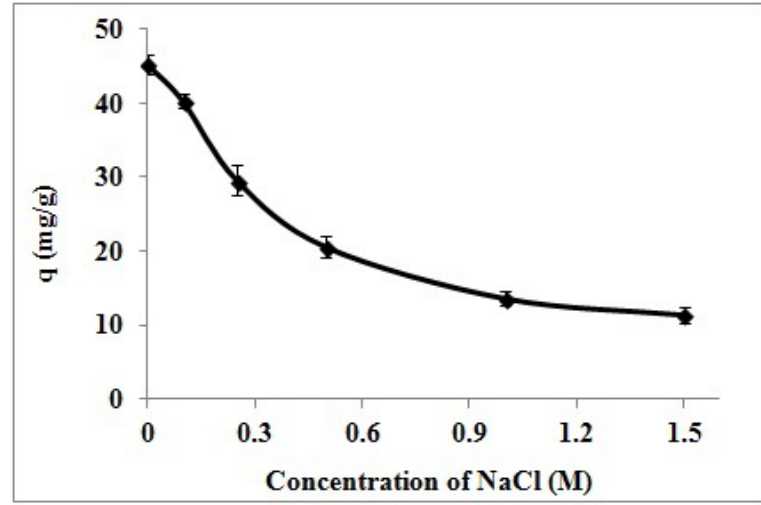

Figure 7. Effect of ionic strength on adsorption ( $\mathrm{pH}: 6.0$, C.: $10 \mu \mathrm{g} / \mathrm{mL}, \mathrm{t}: 30 \mathrm{~min})$.

\section{Effect of Ionic Strength}

Ionic strength is the most important parameter that effect adsorption capacity. As shown in $\mathrm{Fi}$ gure 7, the amount of serotonin adsorbed onto poly(HEMA-MAT) nanostructures decreased significantly $(74.8 \%, \mathrm{p}<0.05)$ as the $\mathrm{NaCl}$ concentration increased from 0.0 to $1.5 \mathrm{M}$. The interactions between the serotonin molecules can increase because of the increasing repulsive electrostatic interactions between the salt ions with the increasing salt concentration and this results in aggregation and precipitation [52]. This large serotonin aggregates might block the adsorption onto poly(HEMA-MAT) nanostructures and may not permit the other molecule to get near the inner side of polymer, and hence the reduced serotonin adsorption capacity can be expected.

\section{Desorption Studies and Reusability of the Poly (HEMA-MAT) Nanostructures}

In order to desorb serotonin from poly(HEMAMAT) nanostructures, different desorption agents (0.5-1.5 M NaCl, 0.5-1.5 M NaSCN and 1\%TEA) were examined in a batch system. The desorption using 0.5 and $1.0 \mathrm{M} \mathrm{NaCl}, 0.5-1.5 \mathrm{M} \mathrm{NaSCN}$ and $1 \%$ TEA was affectless, however using $1.5 \mathrm{M} \mathrm{NaCL}$ more than $90.0 \%$ of the adsorbed serotonin was desorbed from the poly(HEMA-MAT) nanostructures. As mentioned in the result of ionic strength effect, adsorbed amounts of serotonin decreased as salt concentrations increased at $\mathrm{pH} 6.0$, because of the aggregation of serotonin molecules. Another possible explanation for the observation of higher desorption with $1.5 \mathrm{M} \mathrm{NaCl}$ may be like that sodium chloride is a stronger water structure 


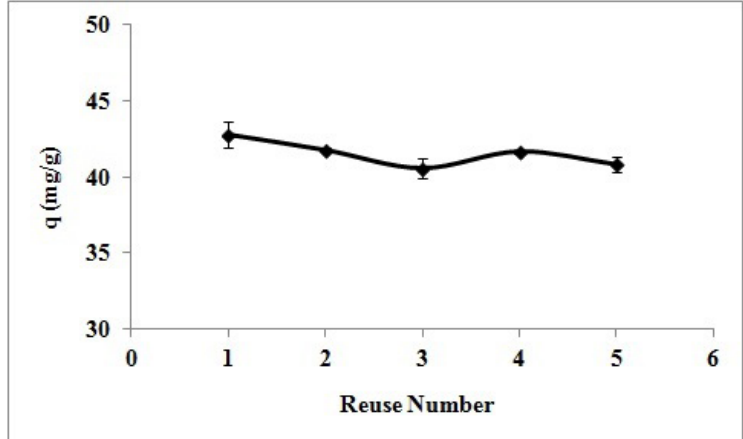

Figure8. Repeated use of Poly(HEMA-MAT) nanostructures $\left(\mathrm{pH}: 6.0, \mathrm{C}_{\mathrm{i}}: 10 \mu \mathrm{g} / \mathrm{mL}, \mathrm{t}: 30 \mathrm{~min}\right)$

breaker than sodium thiocyanate, so it has greater capability to promote biomolecule adsorption in the hydrophobic interaction-dominant procedure. On the other hand, it decreases biomolecule binding in the electrostatic system.

The same nanostructures were used for five times in the adsorption-desorption cycle to evaluate the reusability of the poly (HEMAMAT) nanostructures. Remarkable reduce in the adsorption capacity of the nanostructures was not observed (Figure 8). So, it can be concluded that these materials can be used again and again in the serotonin extraction without determinable losses in their initial adsorption capacity.

\section{Extraction of Serotonin from Banana and Tomato Samples}

Serotonin extraction studies from edible plants such as banana and tomato were performed in a batch system for $30 \mathrm{~min}$ at $25^{\circ} \mathrm{C}$ while stirring continuously at the optimized adsorption conditions. Figure 9 shows the typical chromatograms of reference serotonin standard, spiked and unspiked banana and tomato samples. To show the accuracy of serotonin adsorption from food samples, a $5 \mathrm{mg} . \mathrm{L}^{-1}$ serotonin solution was spiked to food samples. The peak area of serotonin in the spiked banana or tomato sample was increased equally depending on the spiked serotonin level (Figure $9 \mathrm{c}$ and f). Adsorption capacities of the poly(HEMA-MAT) nanostructures were determined as $86.26 \mathrm{mg} / \mathrm{g}$ for banana samples and as $36.02 \mathrm{mg} / \mathrm{g}$ for tomato samples, respectively. The desorption percentages were determined as $76.7 \%( \pm 5.4 \%)$ for banana and $91.5 \%( \pm 6.4 \%)$ for tomato $(n=5)$. The accuracy of this extraction method was examined from the results of the recovery by means of standard addition procedure. The mean recovery was obtained as $94.4 \%$ ( \pm 3.4 ) for banana and as $92.0 \%( \pm 2.2 \%)$ for tomato $(n=5)$. With these results, it could be concluded that this extractive procedure allows us to increase the extraction efficiency of serotonin from edible plants reported by literature $[1,53,54]$.

\section{CONCLUSION}

A nano-sized hydrophobic interaction affinity sorbent was prepared by polymerization of HEMA and MAT and applied for the extraction of serotonin from edible plants. Poly(HEMAMAT) nanostructures showed excellent affinity to serotonin and extraction capacity of the nanostructures was higher than that of the literature because of the relatively larger surface area of the nanostructures used in this work. Therefore, we can suggest that the efficiency of extraction of biomolecules from different sources can be enhanced by reduction in the size of sorbent materials. The time needed to reach equilibrium was about $30 \mathrm{~min}$, in this case it can be said that the adsorption is relatively fast. This adsorption equilibrium can most probably result from the high interaction between serotonin and the hydrophobic group incorporated into the nanostructures. As known, the reusability of an adsorbent is crucial as a key factor in demonstrating process economics. Desorption ratios obtained with this work were very high (up to $90 \%$ ) and we also determined that poly(HEMAMAT) nanostructures are suitable for repeated use without remarkable loss of capacity. According to our results, extraction of serotonin from edible plants can be achieved more effectively using these nanostructures. As a result, the low cost, less labor intensiveness, high separation efficiency of poly(HEMA-MAT) nanostructures make them most promising synthetic materials for the extraction of serotonin.

\section{ACKNOWLEDGMENTS}

The authors are grateful to the Scientific and Technological Research Council of Turkey (TBAG/110T499) for financial support. 

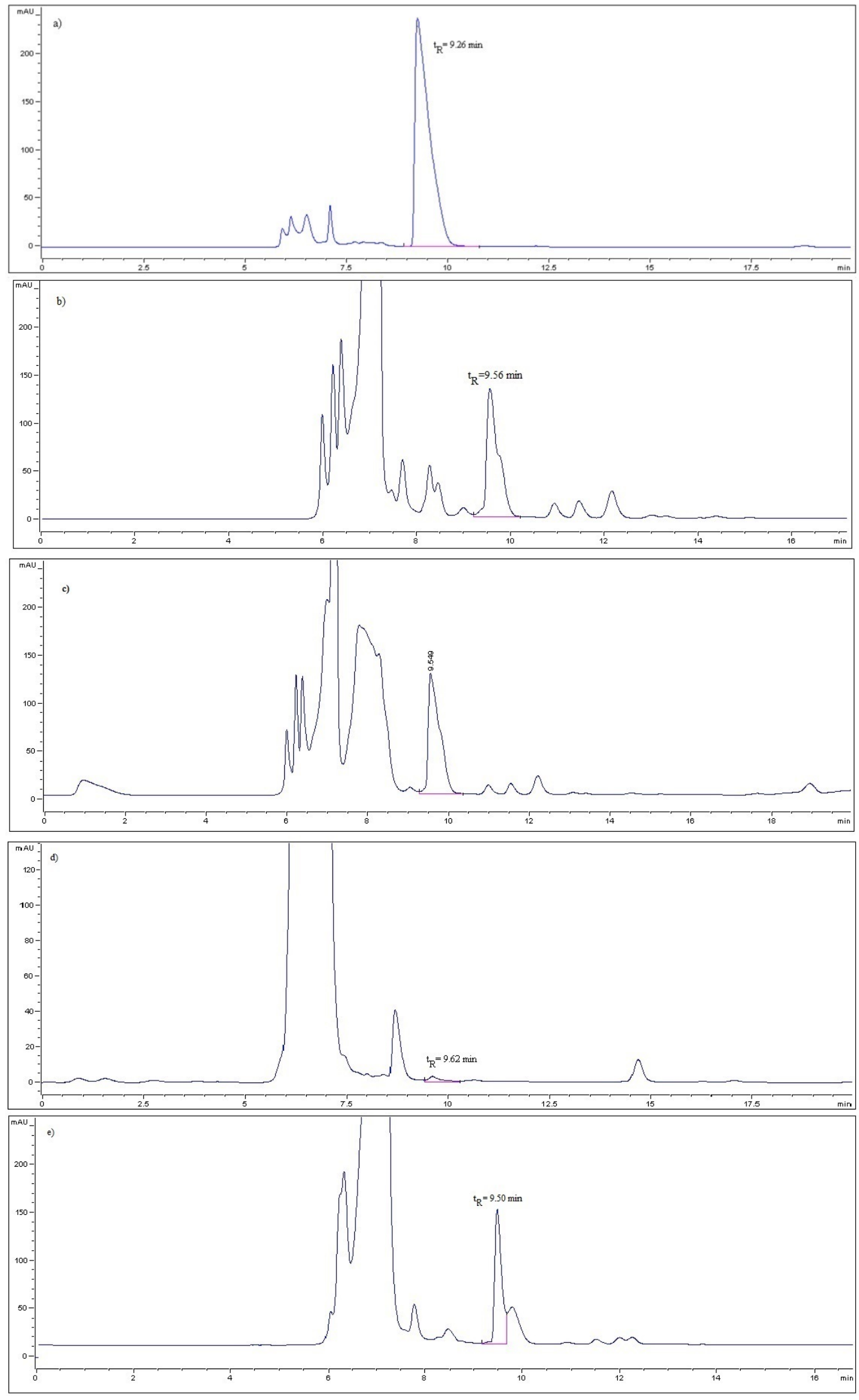

Figure 9. HPLC chromatograms of serotonin a) Standard solution of serotonin at $10 \mu \mathrm{g} / \mathrm{mL}$ b) Direct tomato sample before adsorption c) Serotonin spiked tomato sample at $5 \mu \mathrm{g} / \mathrm{mL}$ d) Direct tomato sample after adsorption e) Direct banana sample before adsorption f) Serotonin spiked banana sample at $5 \mu \mathrm{g} / \mathrm{mL} . \mathrm{g}$ ) Direct banana sample after adsorption (conditions as: $\mathrm{pH}: 6.0, \mathrm{T:} 2{ }^{\circ} \mathrm{C}$, flow rate: $0.5 \mathrm{~mL} / \mathrm{min}$ ). 


\section{References}

1. X. Huang, G. Mazza, Application of LC and LC-MS to the analysis of melatonin and serotonin in edible plants, Crit. Rev. Food Sci., 51 (2011) 269-284.

2. A. Frazer, J.G. Hensler, (1999), in Basic Neurochemistry, Understanding the neuroanatomical organization of serotonin cells in brain provides insight into functions of this neurotransmitter (Siegel, G.J., Agranoff, B. W., Fisher, S.K., Albers, R.W. and Uhle, M.D., ed.), Lippincott Williams and Wilkins, Baltimore, MD. pp. 264-268.

3. Z.D. Peterson, M.L. Lee, S.W. Graves, Determination of serotonin and its precursors in human plasma by capillary electrophoresis-electrospray ionizationtime-of-flight mass spectrometry, J. Chromatogr. B, 810 (2004) 101-110.

4. P.J. Monaghan, H.A. Brown, L.A. Houghtond, B.G. Keevil, Measurement of serotonin in platelet depleted plasma by liquid chromatography tandem mass spectrometry, J. Chromatogr. B, 877 (2009) 2163 2167.

5. A.C.C.L. Martins, M.B.A. Gloria, Changes on the levels of serotonin precursors-tryptophan and 5-hydroxytryptophan-during roasting of Arabica and Robusta coffee, Food Chem., 118 (2010) 529-533.

6. D.L. Taylor, Close-up on serotonin. Learn how this key neurotransmitter influences moods and behavior Nursing, 25 (1995) 64.

7. M.T. Salvador, M.D. Murillo, M.C. Rodriguez-Yoldi, A.I. Alcade, J.E. Mesonero, M.J. Rodriguez-Yoldi, Effects of serotonin on the physiology of the rabbit small intestine, Can. J. Physiol. Pharmacol., 78 (2000) 359-366.

8. R. Pelagio-Flores, R. Ortíz-Castro, A. Méndez-Bravo, L. Macías-Rodríguez, J. López-Bucio, Serotonin, a tryptophan-derived signal conserved in plants and animals, regulates root system architecture probably acting as a natural auxin inhibitor in Arabidopsis thaliana, Plant Cell Physiology, 52 (2011) 490-508.

9. S.D. Paredes, A. Korkmaz, L.C. Manchester, D.X. Tan, R.J. Reiter, Phytomelatonin, a review. J. Exp. Bot., 60 (2009) 57-69.

10. A.I. Romero-Pérez, R.M. Lamuela-Raventós, C. Andrés-Lacueva, M.C. Torre-Boronat, Method for the Quantitative Extraction of Resveratrol and Piceid Isomers in Grape Berry Skins. Effect of Powdery Mildew on the Stilbene Content, J. Agric. Food Chem. 49 (2001) 210-215.

11. F.S. Hosseinian, W. Li, T. Beta, Measurement of anthocyanins and other phytochemicals in purple wheat, Food Chem., 109 (2008) 916-924.

12. D. Ly, K. Kang, J.Y. Choi, A. Ishihara, K. Back, S.G. Lee, HPLC Analysis of Serotonin, Tryptamine, Tyramine, and the Hydroxycinnamic Acid Amides of Serotonin and Tyramine in Food Vegetables, J. Med. Food, 11 (2008) 385-389.

13. R.J. Reiter, L.C. Manchester, D.X. Tan, Melatonin in walnuts, influence on levels of melatonin and total antioxidant capacity of blood, Nutrition, 21 (2005) 920-924.

14. C. Zettersten, M. Co, S. Wende, C. Turner, L. P.J.R. Nyholm, Sjöberg, Identification and Characterization of Polyphenolic Antioxidants Using On-Line Liquid Chromatography, Electrochemistry, and Electrospray Ionization Tandem Mass Spectrometry, Anal. Chem. 81 (2009) 8968-8977.
15. T. Lavizzari, M.T. Veciana-Nogués, S. Bover-Cid, A. Mariné-Font, M.C. Vidal-Carou, Improved method for the determination of biogenic amines and polyamines in vegetable products by ion-pair high-performance liquid chromatography, J. Chromatogr. A, 1129 (2006) 67-72.

16. C. Pape, K. Lüning, Quantification of melatonin in phototrophic organisms, J. Pineal. Res., 41 (2006) 157-165.

17. A. Moreno, M. Castro, E. Falqué, Evolution of trans- and cis -resveratrol content in red grapes (Vitis vinifera L. cv Mencía, Albarello and Merenzao) during ripening, Eur. Food Res. Technol., 227 (2008) 667-674.

18. J. Islam, H. Shirakawa, T.K. Nguyen, H. Aso, M. Komai, Simultaneous analysis of serotonin, tryptophan and tryptamine levels in common fresh fruits and vegetables in Japan using fluorescence HPLC, Food Bioscience, 13 (2016) 56-59.

19. N. Kato, T. Kojima, S. Yoshiyagawa, H. Ohta, A. Toriba, H. Nishimura, K. Hayakawa, Rapid and sensitive determination of tryptophan, serotonin and psychoactive tryptamines by thin-layer chromatography/fluorescence detection, J. Chromatogr. A, 1145 (2007) 229-233.

20. C.H. Lin, Y.H. Chen, On-line identification of trans- and cis-resveratrol by nonaqueous capillary electrophoresis/ fluorescence spectroscopy at $77 \mathrm{~K}$, Electrophoresis, 22 (2001) 2574-2579.

21. L.Y. Gao, Q.C. Chu, J.N. Ye, Determination of transResveratrol in wines, herbs and health food by capillary electrophoresis with electrochemical detection, Food Chem., 78 (2002) 255-260.

22. P.W. Stege, L.L. Sombra, G. Messina, L.D. Martinez, M.F. Silva, Determination of melatonin in wine and plant extracts by capillary electrochromatography with immobilized carboxylic multi-walled carbon nanotubes as stationary phase, Electrophoresis, 31 (2010) 2242-2248.

23. F.A. Badria, Melatonin, Serotonin, and Tryptamine in Some Egyptian Food and Medicinal Plants, J. Med. Food, 5 (2002) 153-157.

24. A.S. Ragab, J.V. Fleet, B. Jankowski, J.H. Park, S.C. Bobzin, Detection and quantitation of resveratrol in tomato fruit (Lycopersicon esculentum Mill.), J. Agric. Food Chem., 54 (2006) 7175-7179.

25. Y. Zhang, M. Mei, X. Huang, D. Yuan, Extraction of trace nitrophenols in environmental water samples using boronate affinity sorbent, Anal. Chim. Acta, 899 (2015) 75-84.

26. E. Bektaşoğlu, E.B. Özkütük, A. Ersöz, R. Say, Development of New Molecular Imprinted Solid Phase Extraction Material for Dimethoate, Spectroscopy Letters, 47 (2014) 168-176.

27. J.A. Padilla-Sanchez, P. Plaza-Bolanos, R. RomeroGonzalez, N. Barco-Bonilla, J.L. Martínez-Vidal, A. Garrido-Frenich, Simultaneous analysis of chlorophenols, alkylphenols, nitrophenols and cresols in wastewater effluents, using solid phase extraction and further determination by gas chromatography tandem mass spectrometry, Talanta, 85 (2011) 23972404.

28. X.J. Huang, D.X. Yuan, Recent developments of extraction and microextraction technologies with porous monoliths, Crit. Rev. Anal. Chem., 42 (2012) 38-49. 
29. Q. Liu, J.B. Shi, L.X. Zeng, T. Wang, Y.Q. Cai, G.B. Jiang, Evaluation of graphene asan advantageous adsorbent for solid-phase extraction with chlorophenols as model analytes, J. Chromatogr. A, 1218 (2011) 197-204.

30. S.Y. Ali, A.M. Sayyar, A. Amirhassan, Determination of monocyclic aromatic amines using headspace solid phase microextraction based on sol-gel technique prior to GC, J. Sep. Sci., 36 (2013) 1629-1635.

31. Y.J. Meng, J.L. Anderson, Tuning the selectivity of polymeric ionic liquid sorbent coatings for the extraction of polycyclic aromatic hydrocarbons using solid-phase microextraction, J. Chromatogr. A, 1217 (2010) 6143-6152.

32. F.J.V. Gomez, I.G. Hernández, S. Cerutti, M.F. Silva, Solid phase extraction/cyclodextrin-modified micellar electrokinetic chromatography for the analysis of melatonin and related indole compounds in plants Microchem. J., 123 (2015) 22-27.

33. P. Pasko, K.S. Ziaja, B. Muszynska, P. Zagrodzki, Serotonin, melatonin, and certain indole derivatives profiles in rutabaga and kohlrabi seeds, sprouts, bulbs, and roots LWT, Food Sci. Techn., 59 (2014) 740 745.

34. A. Ramakrishna, P. Giridhar, K.U. Sankar, G.A. Ravishankar, Melatonin and serotonin profiles in beans of Coffea species, J. Pineal Res., 52 (2012) 470-476.

35. P. Mohr, \& K. Pommerening, (1985) Affinity Chromatography and Related Practical and Theoretical Aspects. Chromatographic Science Series, Vol. 39. Marcel Dekker Inc., New York, pp.320.

36. M.H. Liao, D.H. Chen, Fast and efficient adsorption/ desorption of protein by a novel magnetic nanoadsorbent, Biotechnol. Lett., 24 (2002) 1913-1917.

37. N. Ozturk, S. Akgol, M. Arisoy, A. Denizli, Reversible adsorption of lipase on novel hydrophobic nanospheres, Sep. Purif. Technol., 58 (2007)83-90.

38. T. Kalburcu, M.N. Tüzmen, S. Akgöl, A. Denizli, Immobilized metal ion affinity nanospheres for $\alpha$-alpha-amylase immobilization, Turk J. Chem., 38 (2014) $28-40$.

39. I.P. Kema, A.M.J. Schellings, G. Melborg, J.M.C. Hoppenbrouwers, F.A.J. Muskiet, Influence of a Serotonin- and Dopamine-Rich Diet on Platelet Serotonin Content and Urinary Excretion of Biogenic Amines and Their Metabolites, Clin. Chem., 38 (1992) 1730-1736.

40. B.H.J. Hofstee, Protein binding by agarose carrying hydrophobic groups in conjunction with charges, Biophys. Res. Commun., 50 (1973) 751-757.
41. E.B. Stuart, (1993) Hydrophobic Interaction Chromatography, Principles and methods, Amersham Pharmacia Biotech, ISBN 91-970490-4-2.

42. W.R. Melander, Z. El Rassi, C. Horvath, Interplay of hydrophobic and electrostatic interactions in biopolymer chromatography. Effect of salts on the retention of proteins, J. Chromatogr., 469 (1989) 3-27.

43. P. Strop, D. Cechova, V. Tomasek, Model study of hydrophobic interactions of alpha and beta trypsin and alpha-chymotrypsin, J. Chromatogr., 259 (1983) 255-268.

44. Y. Sanz, F. Mulholland, F. Toldra, Purification and Characterization of a Tripeptidase from Lactobacillus sake, J. Agric. Food. Chem., 46 (1998) 349-353.

45. S. Hjerten Some general aspects of hydrophobic interaction chromatography, J. Chromatogr., 87 (1973) 325-331.

46. J. Porath, L. Sundberg, N. Fornstedt, I. Olson, Salting-out in amphiphilic gels as a new approach to hydrophobic adsorption, Nature, 245 (1973) 465-472.

47. M. Tsezos, R.P. Volesky, Biosorption of uranium and thorium, J. Biotechnol. Bioeng., 23 (1987) 583-604.

48. N. Kuyucak, B. Volesky, Accumulation of cobalt by marine alga, J. Biotechnol. Bioeng., 33 (1989) 809814.

49. Z. Aksu, T.A, Kutsal, A bioseparation process for removing $\mathrm{Pb} 2+$ ions from wastewater by using C.vulgaris, J. Chem. Technol. Biot., 52 (1991) 109-118.

50. Z. El Rassi, Recent progress in reversed-phase and hydrophobic interaction chromatography of carbohydrate species, J. Chromatogr. A, 720 (1996) 93-118.

51. Y. Jung, S. Kim, S.J. Park, J.M. Kim, Application of polymer-modified nanoporous silica to adsorbents of uranyl ions, Colloids Surf. A, Physicochem. Eng. Aspects., 313-314 (2008) 162-166.

52. A. Vinu, K.Z. Hossai, G.S. Kumar, V. Sivamurugan, K. Ariga, Adsorption of amino acid on mesoporous molecular sieves, Stud. Surf. Sci. Catal., 156 (2005) 631-636.

53. S. Kang, K. Kang, K. Lee, K. Back, Characterization of tryptamine 5-hydroxylase and serotonin synthesis in rice plants, Plant Cell Rep., 26 (2007) 2009-2015.

54. S. Kang, K. Back, Enriched production of $\mathrm{N}$-hydroxycinnamic acid amides and biogenic amines in pepper (Capsicum annuum) flowers, Scientia Horticulturae, 108 (2006) 337-341. 